\title{
NAS to redo atomic studies found to be flawed
}

\begin{abstract}
Washington. Two congressional agencies have found serious flaws in a 1985 National Academy of Sciences (NAS) study on the health of US servicemen exposed to radiation from atomic bomb tests. The study, which found a lower incidence of cancer in a group of 47,435 so-called 'atomic survivors' than in the general population, inadvertently included 4,500 servicemen who had not participated in the tests and omitted 15,000 who had, the investigations revealed.

In reports issued last month, both agencies - the General Accounting Office (GAO) and the Office of Technology Assessment (OTA) - blame the Defense Nuclear Agency (DNA) for sloppiness in assembling the data. Their reports, commissioned by Senator Alan Cranston (Democrat, California), the chairman of the Committee on Veterans Affairs, conclude that computer and transcription errors led the servicemen to be dropped from or mistakenly included in the agency's database. Although they do not suggest that the missing data would substantially change the 1985 report's conclusions, GAO and OTA argue that the study is important enough to do again, this time correctly.
\end{abstract}

The NAS, aware that the data were incomplete at the time of the study, has also come under fire for not acknowledging the fact. The only caveat was a footnote acknowledging that the readings on the radiation badges worn by many servicemen were not necessarily accurate and should be taken as approximate. The academy was under heavy pressure to complete the studies from veterans' groups, which wanted to confirm preliminary reports of damage, and from the military, which wanted to play down any medical consequences of the tests.

Robert Alvarez, a staff member for the Government Affairs Committee, which is investigating the atomic tests and related issues, says he is concerned that the flaws in the report may tarnish the academy's reputation for impartiality. He notes that the NAS was criticized in 1983 after it also found no excessive rates of cancer in a study of veterans who were in Nagasaki and Hiroshima after the atomic bombs were dropped.

In the 1983 report, the academy decided that the likelihood of a greater incidence of cancer from such low exposure to radiation was too small to justify a full epidemiological study. Instead, it attempted to contact 28 veterans who had claimed that they had developed melanomas. The National Association of Atomic Veterans denounced the report as "medically criminal" when it was revealed that the NAS researchers had discounted nearly half the cases because they could not confirm their location.

Seymour Jablon, one of the coordinators of both the 1983 and 1985 NAS reports and now a researcher at the US National Cancer Institute, recalls that the NAS researchers "had concerns from the very beginning" about the quality of the data in the 1985 study. "The Army data, in particular, were not in very good shape."

In 1979, the Centers for Disease Control found that veterans of one atomic test had twice the expected rate of leukaemia. Veterans' groups seeking medical compensation had hoped that a full study would confirm that link. The Department of Defense, on the other hand, did not believe that the low levels of exposure could cause lasting damage and hoped that the NAS study would disprove such a link. "There was an awful lot of pressure from both sides," Jablon says.

Another problem facing the academy is the fact that soldiers, because of their selec-

tion and training, are normally healthier than the general population. Some have questioned whether the academy took that bias sufficiently into account when it compared cancer deaths among survivors of atomic tests with statistics for US males of the same age.

Despite the flaws, Jablon believes that the study's basic conclusions are correct. Nevertheless, he argues that it should be redone with the new data, if for no other reason than to eliminate the lingering suspicion among veterans that the data were manipulated to avoid finding a cancer link.

In July, the academy agreed to do a $\$ 3.6$ million, four-year follow-up study. It will attempt to avoid the healthy-soldier effect by using non-exposed servicemen as controls.

Christopher Anderson

\section{Japan endorses local touch}

Tokyo. Local governments provide a growing share of public spending on research in Japan, according to the annual white paper (policy document) from the Science and Technology Agency (STA) released earlier this week (29 September).

The white paper is part of recent moves by Japanese science policy-makers to tap the resources of local governments, which in general are in better financial shape than the national government. Their mention in the agency's annual report is a sign that development of local regions is now an important part of national science policy and will no longer be left to initiatives from local governments or individual ministries.

The Council of Science and Technology, Japan's highest science policy-making body, which is chaired by the prime minister, earlier this year emphasized the promotion of science and technology in local regions as part of its call for a doubling of government spending on research. The white paper is a follow-up to that request.

The national government spends a little more than $¥ 2,000$ billion (US $\$ 17$ billion) a year on research, but that total has risen by only a few per cent a year because a national debt of $¥ 174,000$ billion forces the government to put a rigid limit on spending. Local governments, on the other hand, supply a rising share of total government outlay on research - from 15.2 per cent in 1986 to 17.3 per cent in 1990 , according to the white paper — and now spend close to $¥ 400$ billion a year.

It remains true that the great majority of national research institutes, universities and private research institutes remain concentrated in the Kanto region around Tokyo. But some significant efforts to develop the science infrastructure in other local regions of Japan are under way.

The local governments and industry of Osaka, Kyoto and Nara are jointly developing the Kansai 'science city' in the mountains between these three cities. And although it may not deserve to be called a city, the Kansai development contains a significant number of new research institutes already open or nearly open.

Several initiatives have been launched in the past decade to strengthen local regions. MITI has tried to scatter giant science parks, called technopolises, around the country, but few have taken root. Two exceptions are those centred on Kumamoto in Kyushu and in Oita Prefecture, in the same southern island of Japan, which have used local and national government support to attract private and government research institutes.

Local government science policy has so far relied on the initiative of individual units, which has led at times to a duplication of effort. For example, nearly all local governments, regardless of their capabilities, have wanted to jump on the biotechnology bandwagon. To overcome this problem, the Council of Science and Technology has established a forum of high-level local and national government policy-makers.

Among other efforts, STA has formed a quasi-governmental organization to promote regional research, and next year MITI's Agency of Industrial Science and Technology plans to spend more on its regional research institutes outside of Tsukuba.

But each of these must compete with the magnetism of Tokyo. No matter what new institutes or science parks are opened, outlying regions may still find it hard to attract first-class researchers. David Swinbanks 